\title{
Effects of Migration in a Basic Labour Market Model
}

\author{
Hannu Laurila (1) \\ Faculty of Business and Management, Tampere University, Tampere, Finland \\ Email: hannu.laurila(at)tuni.fi
}

How to cite this paper: Laurila, H. (2019) Effects of Migration in a Basic Labour Market Model. Theoretical Economics Letters, 9, 1717-1728.

https://doi.org/10.4236/tel.2019.96109

Received: May 29, 2019

Accepted: July 30, 2019

Published: August 2, 2019

Copyright $\odot 2019$ by author(s) and Scientific Research Publishing Inc. This work is licensed under the Creative Commons Attribution International License (CC BY 4.0).

http://creativecommons.org/licenses/by/4.0/

\begin{abstract}
This paper tackles the textbook message that free migration of labour equalizes real wages between local labour markets, since nominal wages should rise and prices should fall in emigrating localities and vice versa in immigrating localities. Reverse price adjustments should thus help in stabilizing migration. The paper investigates the idea in a basic labour market model with sequential comparative statics, and gets conflicting findings: both decreasing prices in the emigrating end and increasing prices in the immigrating end foster emigration. Furthermore, common wisdom is that, if emigration forces the locality to elevate tax rates, people's voting with feet should foster emigration. This paper shows that this is true only with notable tax increases. In the other end, induced emigration appears if the initially immigrating locality is forced to increase its taxes, even modestly.
\end{abstract}

\section{Keywords}

Labour Migration, Nominal Wages, Prices, Taxation

\section{Introduction}

People's everyday welfare is highly place-dependent, and residential choice is an important part of individual welfare maximization. A common textbook presentation (see [1], pp. 600-609; [2], pp. 140-147; [3], pp. 192-197; [4], pp. 102-105) of that choice is a partial equilibrium analysis of people's migration between labour markets. In that framework, migration reflects people's residential choices as responses to differences in real wages between local labour markets. Thus, the triggering of migration is treated in terms of exogenous market parameters, that is nominal wages and consumption prices that enter into the budget constraint. This is reasonable because labour income is crucial for average people, and real wage, which is nominal wages divided by consumption prices is a simple and 
empirically useful measure of welfare. The local nature of the labour market also constitutes a spatially relevant scene for migration analysis, and labour units are easily transferrable to numbers of people.

The main idea of the labour market model is that real wage equalization produces a stable and efficient market solution. In the process, both nominal wages and consumption prices adjust so that welfare differences disappear and systematic migration ends. Thus, a decline in local prices should dampen emigration and an increase in local prices should dampen immigration. A common view also is that taxes affect welfare comparisons between localities thus inducing people to vote with their feet. In particular, the emigrating localities may be forced to elevate their taxes, which should then cause a further boost on emigration.

This paper examines these questions by taking a closer look on the basic labour market model (cf. [5]). The paper proceeds as follows. Section 2 constructs the model. Section 3 presents the migration equilibrium between two localities based on nominal wage adjustment, and then carries out sequential comparative static analyses of the effects of price and tax changes. By now, the sequential approach seems to be novel in the literature.

The findings from the sequential analysis somewhat contradict the common wisdom by showing that a price decrease in the emigrating locality, as well as a price rise in the immigrating locality rather foster than dampen emigration. Moreover, a reasonably modest tax increase in the emigrating locality does not foster emigration, whereas even a small tax increase in the originally immigrating locality turns the migration flow backwards. Section 4 concludes the findings.

\section{The Basic Model}

Following the usual procedure in the textbook literature (see [6], pp. 383-390; [7], pp. 158-179; [8], pp. 464-588), ignore non-labour income, normalize total available time to unity, and compress locally produced and consumed private and public goods into one consumption bundle as perfect substitutes. Write

$$
\operatorname{Max} U(q, 1-l) \text { s.t.lw }=p q
$$

for the individual maximization problem. In Equation (1), $q$ is consumption, $1-1$ is leisure and $l$ is time used in work, $w$ is nominal wage, and $p$ is consumption price, including the tax price of local public goods. From the budget constraint $q$ $=1 \mathrm{w} / \mathrm{p}$, where $\mathrm{w} / \mathrm{p}$ is the real wage. Assume that the qualitative aspects of leisure, work and consumption are all included in the market information (the real wage), determined in competitive local labour markets. Local supply of labour derives from individual time use decisions, yielding the first order optimum condition $w=p U_{2} / U_{1}$, where the subscripts 1 and 2 indicate the derivatives against the first and second argument of the utility function, respectively. The aggregate labour supply can be written in inverse form (see [9], pp. 7-8) as

$$
w=p g(L),
$$

where $L$ denotes total labour time and $g(L)$ describes people's market valuation 
of time. Assuming that substitution effects dominate income effects $(\mathrm{d} g / \mathrm{d} L>0)$, the labour supply curve is upward sloping in $L-w$ space.

Local labour demand depends on the capability of the local production sector to hire labour. Assume that local production, including both private and public goods, operates competitively under profit maximization.

$$
\operatorname{Max} \pi=(1-t) p q-w L,
$$

where $t$ is the tax rate. The production sector consists of private firms that produce private goods, and public organizations that produce public goods. Both operate efficiently, obeying Equation (3). Private firms get sales revenue from private goods, while public firms' revenue consists of taxes paid by the working residents. A practical interpretation of Equation (3) is that taxes are deducted from wages and channeled to finance public production. Thus, the tax rate $t$ can be regarded as the public sector's share of the local economy. Moreover, assume that the tax system is fair so that the workers who pay the taxes also receive the corresponding tax financed benefits. The private and public firms use equal technology.

$$
q=f(K, L),
$$

where $K$ denotes the local capital stock. The usual assumptions on the production function apply. Technically, the factors $K$ and $L$ are perfectly elastic between private and public production, but there may be some friction in the short term. Keeping the capital stock is constant in the short term, optimization on labor use yields.

$$
w=(1-t) p f_{L}
$$

for the market demand for labour, saying that the nominal wage equals the market value of marginal physical product of labour $f_{L}$ in the optimum. By the assumption of diminishing marginal product, the market demand curve is downward sloping in $L-W$ space. The slope of the curve depends on local industrial structure and technology.

The next chapter presents a graphical model of two localities based on Equations (1)-(5). In particular, Equations (2) and (5) say that the analysis is conducted in nominal terms in order to tackle the question of the separate adjustment of nominal wages and consumption prices. Thus, the graphs are presented in $L-W$ space, where the labour force variable $L$ is transferrable to numbers of migrating people.

\section{Effects of Migration}

\subsection{Initial Migration Equilibrium}

The economy consists of two localities A and B with self-sustaining labour markets. Ignore trade in both private and public goods, and assume that production and capital are immobile between the localities and owned by the residents of each locality. That is, only people are perfectly mobile between the localities ac- 
cording to possible differences in labour market conditions. Assume also that prices are fixed in the short run so that the nominal wage represents also the real wage and there are no changes in taxation in either locality.

Figure 1 illustrates the setting, where market circumstances differ between the localities thus triggering migration. The left panel presents the labour market in locality A, and the right panel presents the labour market in locality B. The middle panel presents the sur-local labour market. The upper set of the three panels describes the market adjustment with welfare effects, and the lower set of the panels exposes the outcome in the market circumstances.

In the upper section of Figure 1, the labour demand graphs $D^{A}=\left(1-t^{A}\right) p^{A} g^{A}\left(L^{A}\right)$

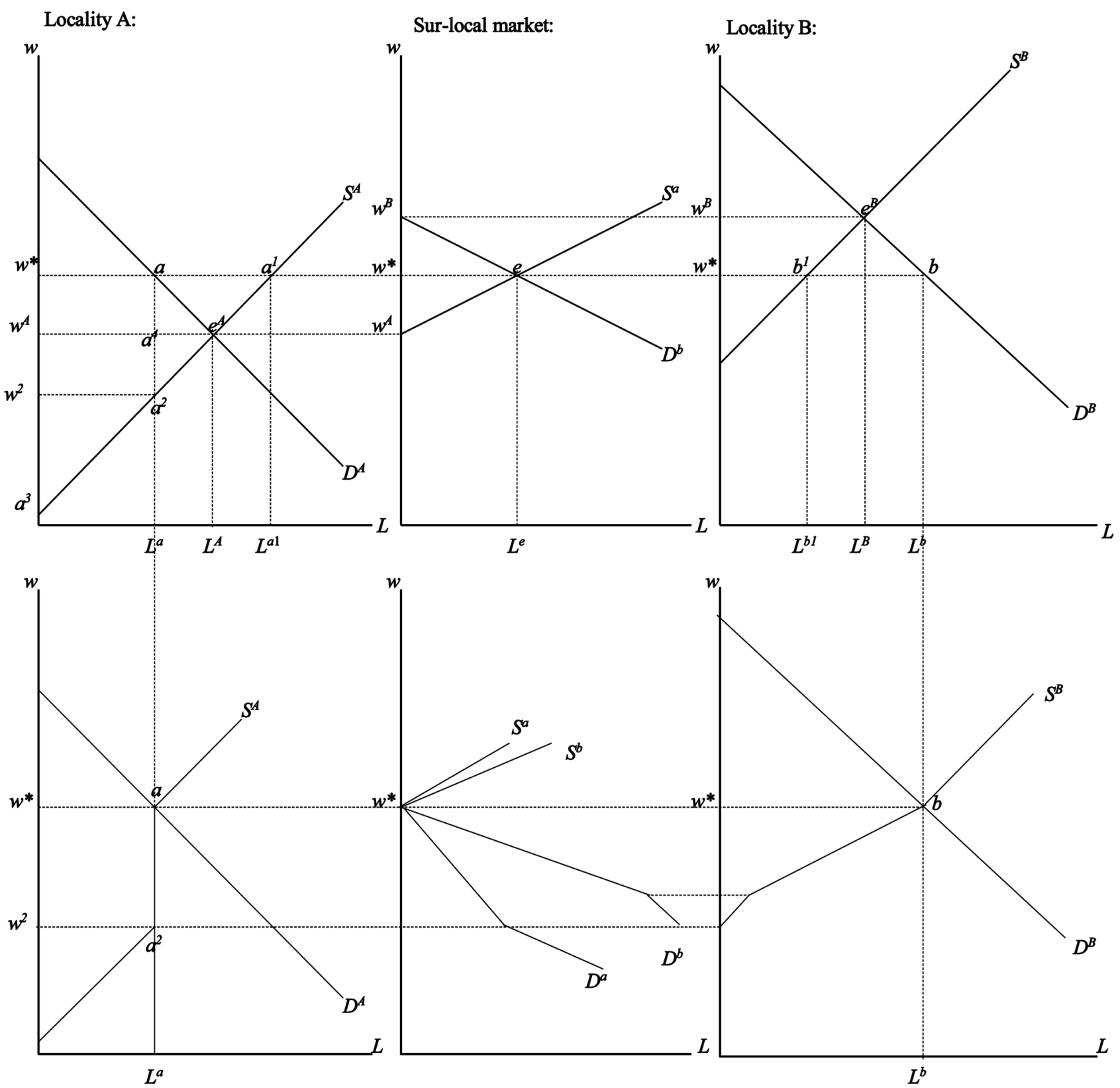

Figure 1. Comparative static effects of migration. 
and $D^{B}=\left(1-t^{B}\right) p^{B} g^{B}\left(L^{B}\right)$ differ due to different capital stocks and industrial structures, and the labour supply graphs $S^{A}=p^{A} f_{L}^{A}$ and $S^{B}=p^{B} f_{L}^{B}$ differ because of demographic, occupational and other such reasons. The initial equilibrium in $\mathrm{A}$ is in $e^{A}$ at $w^{A}$ and that in $\mathrm{B}$ is in $e^{B}$ at $w^{B}$. This means that some people in $\mathrm{A}$ are willing to work for higher wages in $\mathrm{B}$, while some firms in $\mathrm{B}$ are willing to hire lower-cost labour from A. The middle panel presents these motives. The market supply curve $S^{a}$ (the horizontal gap between $S^{4}$ and $D^{4}$ ) describes the excess labour supply from A for wages higher than $W^{A}$, and the market demand curve $D^{b}$ (the gap between $D^{B}$ and $S^{B}$ ) describes the excess labour demand from $B$ for wages lower than $w^{B}$. Since there are no changes in prices and taxes, wages rise in $\mathrm{A}$ and fall in $\mathrm{B}$ until the market equilibrium $e$ in the middle panel is reached at $W^{*}$. Employment is $L^{a}$ in $\mathrm{A}$, and $L^{b}$ in B. Emigration from $\mathrm{A}$ is $L^{a 1}-L^{a}$ and immigration to $\mathrm{B}$ is $L^{b}-L^{b 1}$, which displaces $L^{B}-L^{b 1}$ of original workers. Thus, $L^{a 1}-L^{a}=L^{b}-L^{b 1}=L^{e}$. In A, firms lose $W^{A} W^{*} a e^{A}$, of which $W^{A} W^{*} a a^{4}$ goes to the staying workers, whose surplus is $a^{3} W^{*} a a^{2}$. The net welfare loss in $\mathrm{A}$ is $a^{2} a e^{A}$. In $\mathrm{B}$, firms gain $w^{*} w^{B} e^{B} b$ of which $w^{*} w^{B} e^{B} b^{1}$ comes from the original workers so that the net gain is $b^{1} e^{B} b$. The emigrants' gain is $a^{2} a a^{1}$, carried from A to B. Since it overwhelms the welfare loss in A, $a a^{1} e^{A}$ measures the net welfare effect of emigration. Total welfare gain is $W^{A} W^{B} e$ in the middle panel, of which $w^{A} W^{*} e$ equals $a a^{1} e^{A}$ in the left panel and $w^{*} W^{B} e$ equals $b^{1} e^{B} b$ in the right panel. The economy wide resource allocation is efficient.

Note that the effects depend on local market conditions. First, the more capital intensive the local industrial structure compared to the rest of the economy the steeper the local labour demand curve and thus the exess supply curve to the sur-local market. Local wages adjust more, and migration flows and welfare effects are smaller than in Figure 1. Second, the smaller the local labour force with respect to the rest of the economy the flatter the labour demand curve faced in the sur-local market. Then, all effects are magnified compared to those in Figure 1.

\subsection{Adjustment of Prices}

It is quite plausible and empirically reasonable that migration induces price changes in both ends of migration. As people exit a locality, local demand for goods decreases. Recalling the assumption of immobile production and exclusion of trade, market prices are due to fall. The opposite is reasonable in the immigration end. Note that the standard model in Figure 1 is constructed from Equations (2) and (5) with the assumption of fixed prices and taxes so that market adjustment is based wholly on flexible nominal wages. The ceteris paribus assumption is necessary in this kind of a framework. Therefore, comparative static investigation of the role of price adjustment must be done in sequential manner. Take the lower section of Figure 1, let also prices adjust, but keep the assumption of fixed taxes and examine what happens, if there occur price changes in $\mathrm{A}$ or $\mathrm{B}$.

Figure 2 illustrates the effects of a price fall in locality A, taking prices in 


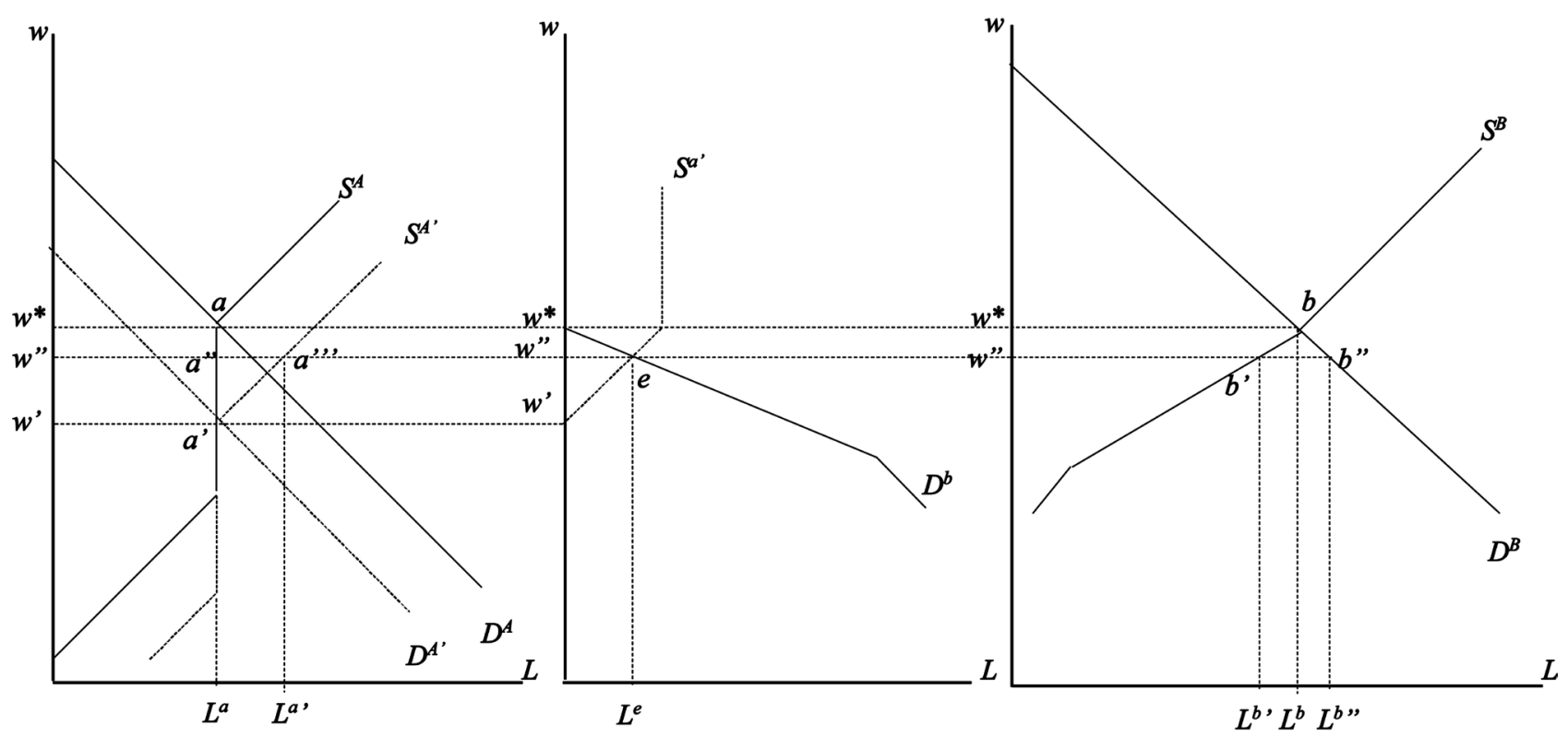

Figure 2. Effects of a price decline in locality A.

locality B fixed. For illustrational ease, it is assumed that the price change keeps the real wage unaltered. That is, the nominal wage in A adjusts simultaneously so that the local labour supply and labour demand equality remains at $L^{a}$ as a response to the price change compelled by emigration. This is also the idea of the "disequilibrium model" in [4] (pp. 192-193).

In the left panel of Figure 2, the decline in prices in A makes labour demand shift inwards to $D^{A^{\prime}}$ and labour supply shift outwards to $S^{A^{\prime}}$. Nominal wage adjusts to $w^{\prime}$, and the new labour market equilibrium in $\mathrm{A}$ is at $a^{\prime}$. This produces excess labour supply, shown by the dashed graph $S^{a^{\prime}}$ in the middle panel. The nominal wage readjusts to $w^{\prime \prime}$ and the market equilibrium is at $e$. The outcome is migration from $\mathrm{A}$ to $\mathrm{B}$ with $L^{a^{\prime}}-L^{a}=L^{e}=L^{b^{\prime \prime}}-L^{b^{\prime}}$. This causes positive welfare effects: productional gain in B measured by $b b^{\prime \prime} b^{\prime}=w^{*} e w^{\prime}$ plus the emigrants' gain measured by $a^{\prime \prime} a^{\prime \prime \prime} a^{\prime}=w^{\prime \prime} e w^{\prime}$. The finding is that the price fall in the emigrating community induces further emigration, which contradicts the common sense that a decline in local prices should alleviate people's motives for deserting the locality. Moreover, the induced emigration creates positive welfare effects in the economy even though the price change did not affect the real wage in locality $\mathrm{A}$.

Second, consider the effects of a migration induced price rise in locality B, keeping prices in A fixed. Figure 3 illustrates such effects under the assumption that the real wage in $\mathrm{B}$ remains unaltered after the rise in prices.

In the right panel of Figure 3, the price change in B makes the labour demand curve shift outwards to $D^{B^{\prime}}$ and the labour supply curve shifts inwards to $S^{B^{\prime}}$. The nominal wage adjusts to $w^{\prime}$ so that the real wage remains unaltered, and the temporary equilibrium is in $b^{\prime}$ at $L^{b}$. This produces the new excess demand graph $D^{b^{\prime}}$ in the middle panel. The nominal wage readjusts then to $w^{\prime \prime}$ yielding 


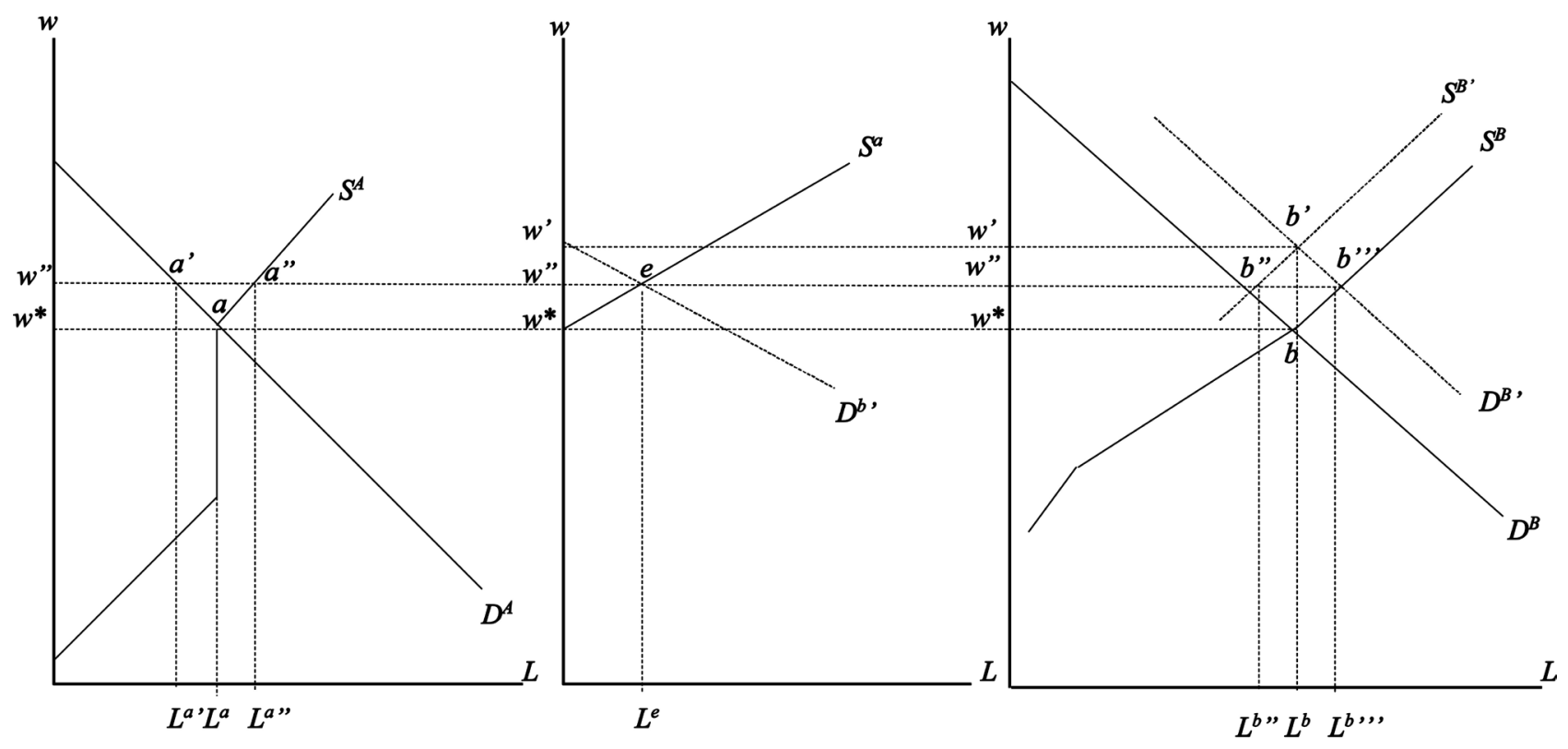

Figure 3. Effects of a price rise in locality B.

the market equilibrium in $e$ in the middle panel. As a result, there occurs emigration from $\mathrm{A}$ to $\mathrm{B}$ so that $L^{a^{\prime \prime}}-L^{a^{\prime}}=L^{e}=L^{b^{\prime \prime \prime}}-L^{b^{\prime \prime}}$, and the welfare effects consist of productional gain $b^{\prime} b^{\prime \prime} b^{\prime \prime}=w^{\prime} e w^{\prime \prime}$ and the emigrants' gain $a^{\prime} a^{\prime \prime} a=w^{\prime \prime} e w^{*}$. The result is again somewhat counterintuitive: even a rise of prices in locality $B$ fosters emigration from $\mathrm{A}$ to $\mathrm{B}$, and causes positive welfare effects in the short-term.

\subsection{Tax Implications}

A common view is that taxes affect welfare comparisons between communities and thus induce people to vote with their feet (see [10]). It is also quite conceivable that while emigration erodes the local tax base, the evolution of service provision and other social and physical infrastructure may lag behind thus causing financial strain in the short term. Another angle is that also immigrating communities may face short-term budgetary problems because of increased need for local public services and investments in infrastructures thus urging elevation of local taxes.

Consider first the effects of an emigration induced tax increase in locality A, keeping the price of the consumption bundle $p$ fixed. Emigration from A means a decline in total production, consisting of private and public goods. Assume that the fall in total production treats private and public goods asymmetrically thus causing changes in the share of public production, measured by the tax rate $t$. This is reasonable, because public goods include inflexible physical and social infrastructures. Thus, due to emigration, the production factors must shift partially from private to public production, which makes the share of public goods (the tax rate $t$ ) rise. Recall that private and public goods are perfect substitutes, and the tax system is fair so that the tax payers (that is workers) also receive the corresponding benefits. Figure 4 presents comparative static effects of a tax rise 


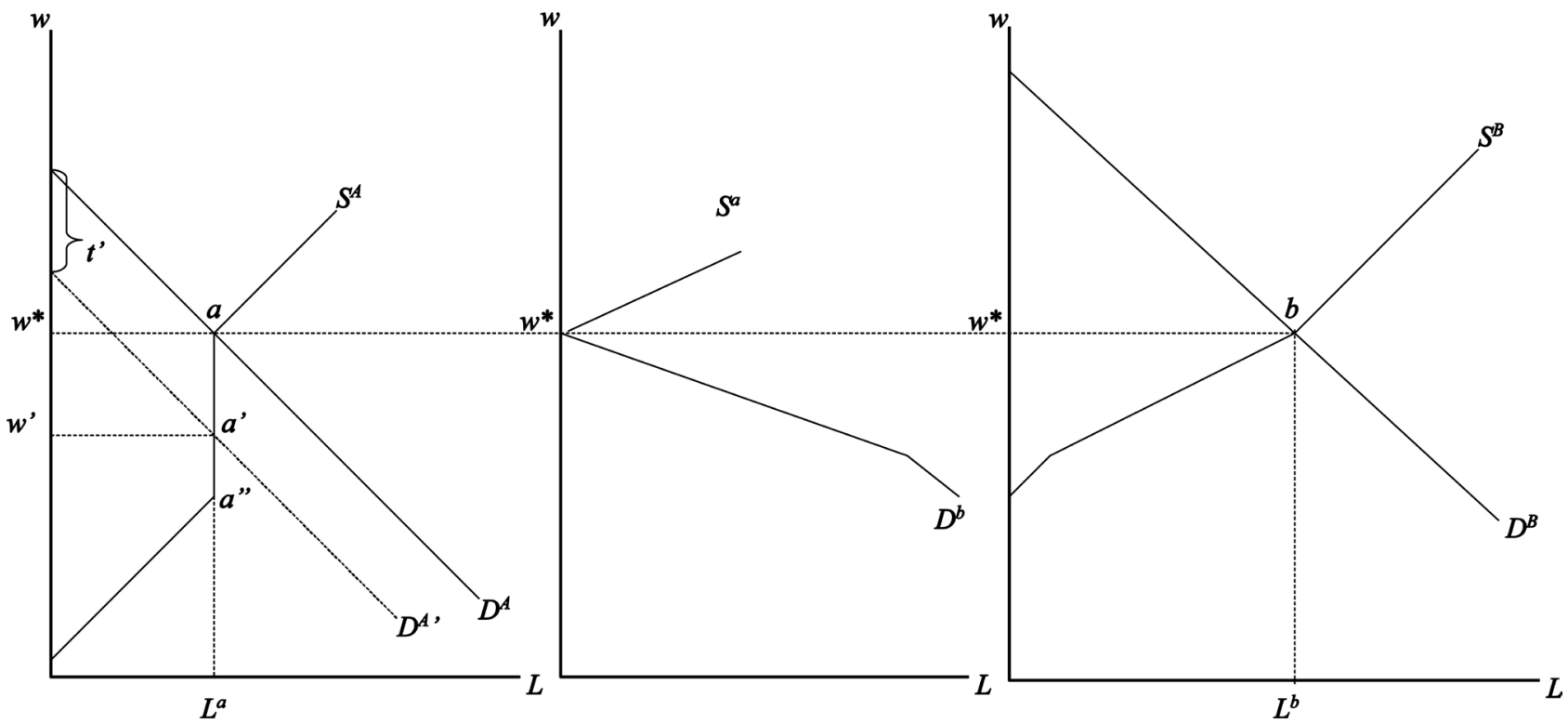

Figure 4. Effects of a modest tax rise in locality A.

in A for a modest tax increase from $t$ to $t^{\prime}$.

In Figure 4, a small tax rise from $t$ to $t^{\prime}$ shifts the labour demand curve inwards from $D^{A}$ to $D^{A^{\prime}}$ in the left panel. Since $D^{A^{\prime}}$ crosses $S^{A}$ on the vertical segment, there is nobody on the move, and labour demand equals labour supply at $L^{a}$. The nominal wage $w^{\prime}$ is still higher than the requirement wage given by the rising segment of $S^{A}$ up till $a^{\prime \prime}$. Moreover, there has occurred only a reverse change in the shares of perfectly substitutable private and public goods. Since the production of public goods is covered by the tax revenue $t^{\prime} L^{a}$, and they are delivered free of charge back to the working residents (the area $w^{*} a a^{\prime} w^{\prime}$ ), their purchasing power actually equals $w^{*}$. Since taxation does not affect migration, there are no effects in the sur-local labour market, in locality B, or on welfare. The finding is that a modest tax increase induced by emigration does not affect migration in the short term. Figure 5 presents the respective effects of a more notable tax increase to $t^{\prime \prime}$.

In Figure 5, tax rate $t^{\prime \prime}$ in locality A makes the labour demand curve shift from $D^{4}$ to $D^{A \prime}$. The local equilibrium settles to $a^{\prime \prime}$ as the attainable wage adjusts to $w^{\prime \prime}$. Labour demand falls thus making $L^{a}-L^{a \prime}$ emigrate to $\mathrm{B}$. The net wage $w^{\prime \prime}$ is lower than $w^{*}$, but the tax financed public provision means that purchasing power is $w^{\prime}$, which exceeds $w^{*}$. Emigration depicted by the segment $a^{\prime \prime} a^{\prime \prime \prime}$ of $S^{4}$ in the left panel produces the dashed curvature $w^{\prime \prime} e^{\prime \prime} e^{\prime} w^{\prime}$ of $S^{a}$ in the middle panel (since $w^{\prime}>w^{*}>w^{\prime \prime}$ ). The market equilibrium settles to $e$ as the market wage adjusts to $W^{f}$. In locality B, the fall of wages to $w^{f}$ drives $L^{b}-L^{b^{\prime}}$ of the original workers out from working, but the new immigrants $\left(L^{a}-L^{a^{\prime \prime}}=L^{b^{\prime \prime}}-L^{b^{\prime}}\right)$ more than replacing them thus increasing employment to $L^{b^{\prime \prime}}$. Welfare in A decreases by $a^{\prime} a a^{\prime \prime \prime} a^{\prime \prime}$, while the firms in B gain $b b^{\prime \prime} b^{\prime}=w^{*} e w^{e}$, and the new immigrants' gain is $w^{e} e e^{\prime \prime} w^{\prime \prime}$. Thus, the welfare loss is $w^{\prime} e^{\prime} e w^{*}$, which is the cost to the whole economy from the tax-induced market distortion and the consequent 


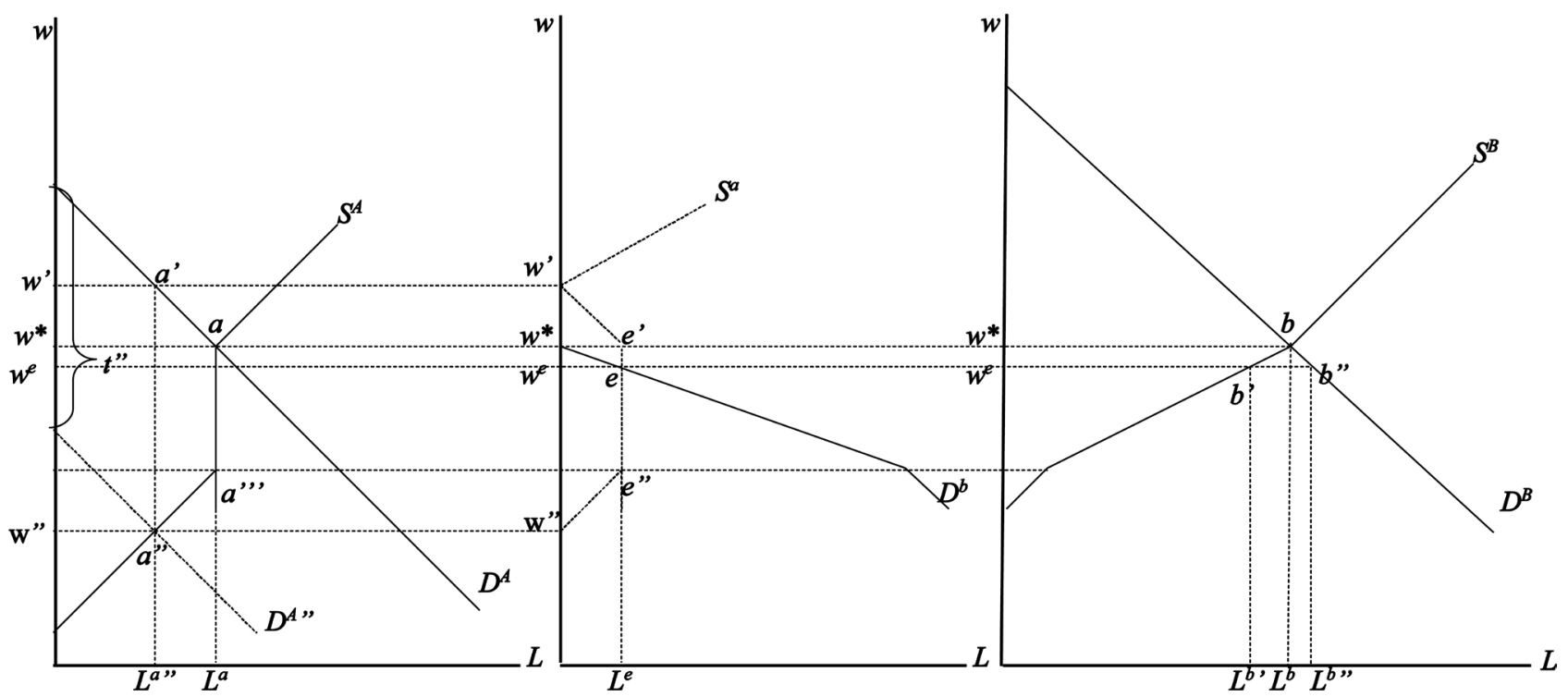

Figure 5. Effects of a notable tax rise in locality A.

inefficiency in resource allocation. The finding is that significant tax increases may foster emigration in the short run.

Note that the effects depend on market conditions. If locality $\mathrm{A}$ is small enough to face a flat sur-local demand curve at $W^{*}$, emigrants' welfare gain is bigger and the welfare loss reduces. Furthermore, if $\mathrm{A}$ is also capital intensive in production so that $D^{4}$ is steeper, $\operatorname{tax} t^{\prime}$ would make its gross wage adjust more and net wage adjust less so that both emigration and welfare effects would be smaller. In a capital intensive locality, taxes can be high without big effects on employment, and the small fall in net wages induces only modest emigration. Quite surprisingly, small capital intensive localities seem to be less vulnerable to taxation than large diverse ones.

Second, consider the effects of a migration induced tax rise in locality B. Figure 6 presents the analysis.

In the right panel of Figure 6, the tax $t^{\prime}$ imposed in B shifts the labour demand curve to $D^{B^{\prime}}$. The local labour market equilibrium should then be at $b^{\prime}$ after the adjustment of the nominal wage to $w^{\prime}$. For analytical purposes, the segment $b^{\prime} b^{\prime \prime \prime}$ of the labour supply curve is shifted correspondingly (because the reference wage is $w^{\prime \prime}>w^{*}>w^{\prime}$ ) to the inter-community labour market, depicted by the dashed segment $w^{\prime} e^{\prime}$ in the middle panel. The sur-local labour market equilibrium is thus reached at $e$ in the middle panel through the adjustment of the market wage to $W^{\mathscr{f}}$, which determines the final migration pattern from A to $\mathrm{B}$ : the amount of people who return from B to A is $L^{b^{\prime \prime \prime}}-L^{b^{\prime}}=L^{e}=L^{a^{\prime}}-L^{a}$, and only $L^{b}-L^{b^{\prime \prime \prime}}$ remain in $\mathrm{B}$, albeit unemployed. Employment in $\mathrm{B}$ is $L^{b^{\prime}}$, and the workers receive free public goods worth of $w^{\prime \prime} b^{\prime \prime} b^{\prime} w^{\prime}$ so that their purchasing power equals $w^{\prime \prime}$. The tax wedge is $w^{\prime \prime} w^{e}$, and the welfare effects are the following: The productional welfare gain in $\mathrm{A}$ is ${w^{*}}^{*} \mathrm{ew}$, and the returnees from B to A gain $w^{e} e w^{\prime}$ so that the total gain is $w^{*} e w^{\prime}$. The net welfare loss, or 

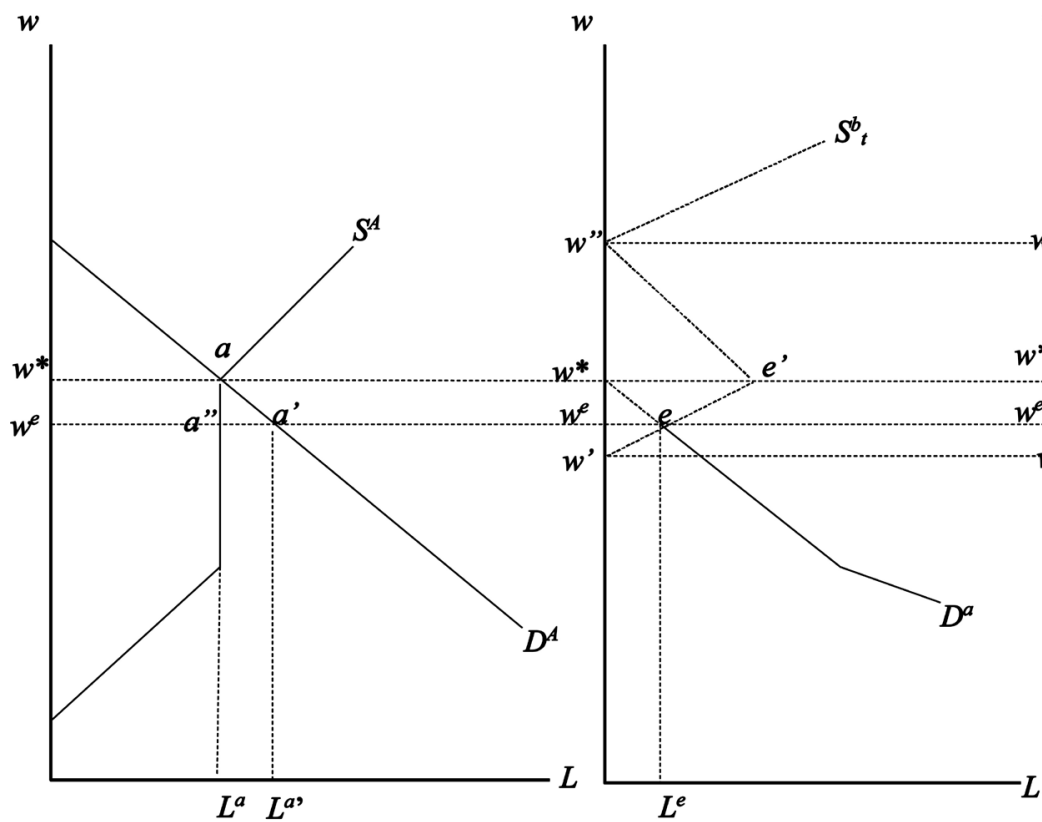

$w$

Figure 6. Effects of a rise in taxes in locality B.

dead weight loss of taxation in the economy thus is $w^{\prime \prime} e^{\prime} e w^{*}$ in the middle panel. The finding is that even modest tax increases cause backward migration thus dampening immigration.

Note that the effects depend again on size and capital intensity. In Figure 6, the migration effect is the greater the smaller $B$ is relative to the rest of the economy. If $B$ is very small and the sur-local demand curve is horizontal, emigration from $B$ grows, the whole welfare gain attaches to the emigrants, and the welfare loss of the whole economy shrinks (note that the welfare effect in B does not depend on its size). Thus, the smaller B the bigger the migration effects and the smaller the welfare effects and vice versa. The role of relative capital intensity can be analyzed by making B's labour demand curve steeper. Taxation would then cause smaller effects on migration, market wages and welfare. Thus, the more capital intensive the industrial structure in B the smaller the economic effects of taxation. The finding is that big immigrating localities with a capital-intensive industrial structure can use taxes without notable effects on migration and welfare.

\section{Conclusions}

The paper scrutinized common conceptions concerning the effects of migration by taking a closer look on the traditional theory of labour market migration. The comparative static analyses were conducted in a sequential manner. First, the migration equilibrium between two localities was constructed according to nominal wage adjustment, and second, price adjustment and the effects of taxation were studied sequentially in that equilibrium setting. The approach seems to be novel in the literature.

The findings are quite surprising. A common thought is that emigration 
makes local consumption demand decrease and market prices fall, and vice versa in the immigration end. However, the sequential analysis showed that if local prices fall due to emigration, it rather enforces than dampens emigration in the short run. This contradicts the common sense that a decline in local prices should alleviate people's motives to emigrate. The same kind of an unorthodox finding rose from the immigration end: a local price rise rather fosters than dampens immigration.

Sequential comparative static analysis of taxes produced also some counterintuitive findings. In particular, an initially emigrating locality can impose modest tax increases without making the still remaining residents vote with their feet. There emerges no dead weight loss either. The tax increase must be decidedly high in order to trigger such effects. This is because past emigration erects a migration threshold, which means that the reservation wage of the remaining workers is considerably lower than the current market wage. The height of the threshold depends on local labour market conditions compared to the rest of the economy. There is no such threshold in immigrating localities, and even a small tax increase turns the migration flow backwards and causes dead weight losses.

In practice, the tax effects may be minor. Even high taxes have trivial effects, if they are used by small and capital-intensive emigrating localities. For example in Finland, most of the declining rural localities belong to this category. In the other end, taxes imposed by big capital intensive immigrating localities have only trivial effects. Finnish growth centers are mostly of this type. Thus, according to the classical migration model, there may be considerable degrees of freedom in local tax policy.

\section{Conflicts of Interest}

The author declares no conflicts of interest regarding the publication of this paper.

\section{References}

[1] Acemoglu, D., Laibson, D. and List, J. (2019) Economics. 2nd Edition, Pearson Education Ltd., Harlow.

[2] Armstrong, H. and Taylor, J. (2002) Regional Economics and Policy. 3rd Edition, Blackwell Publishers, Oxford.

[3] Krugman, P., Obstfeld, M. and Melitz, M. (2015) International Economics, Theory and Policy. 6th Edition, Addison-Wesley Publishing Company, Reading, MA.

[4] McCann, P. (2001) Urban and Regional Economics. Oxford University Press, Oxford.

[5] Laurila, H. (2007) Economics of Migration. VDM Verlag Dr. Müller. Saarbrücken.

[6] Mankiw, N.G. and Taylor, M. (2011) Economics. 2nd Edition, Gengage Learning EMEA, Andover.

[7] Perloff, J. (2018) Microeconomics. 6th Edition, Pearson Education Ltd., Harlow.

[8] Parkin, M. (2019) Economics. 13th Edition, Pearson Education Ltd., Harlow. 
[9] Heijdra, B. and van der Ploeg, F. (2002) Foundations of Modern Macroeconomics. Oxford University Press, New York.

[10] Tiebout, C. (1956) A Pure Theory of Local Expenditures. Journal of Political Economy, 64, 416-424. https://doi.org/10.1086/257839 